\title{
BÀN VỀ PHÉP CHIẾU DÙNG CHO BẢN ĐỒ CHUYÊN ĐỀ CẤP TỈNH
}

\author{
TS. ĐÔNG THỊ BÍCH PHƯO'NG
}

Viện Khoa học Đo đạc và Bản đồ

\section{Tóm tắt}

Bài báo làm rõ một số yếu tố ảnh hưởng đến việc lựa chọn phép chiếu dùng cho bản đồ chuyên đề và đề xuất sử dụng phép chiếu UTM với k=0.9999, kinh tuyến trục địa phương cho nhóm bản đồ chuyên đề từ cấp tỉnh trở xuống. Hướng dẫn áp dụng hệ quy chiếu và hệ tọa độ quốc gia VN-2000 [1] do Tổng cục Địa chính ban hành năm 2001 (Thông tư 973) quy định áp dụng các lưới chiếu dùng cho bản đồ địa hình cơ bản, bản đồ hành chính, bản đồ địa chính. Đây là cơ sở để các ngành, các cấp xây dựng các quy định về co' sở toán học cho các bản đồ chuyên đề phù hợp với mục đích sử dụng, nội dung, phương pháp thể hiện, điều kiện thành lập và sử dụng. Tuy nhiên, sự phát triển của khoa học công nghệ đã mang lại nhiều thay đổi trong thành lập và sử dụng bản đồ, đồng thời làm phát sinh những yêu cầu ngày càng cao đối với sản phẩm bản đồ và thông tin địa lý. Do vậy nhiều quy định hiện hành về cơ sở toán học của bản đồ đã trở nên không phù hợp.

\section{Cơ sở lựa chọn phép chiếu cho bản đồ chuyên để}

Theo mục đích sử dụng, các bản đồ chuyên đề được thành lập trong thời gian qua tại Việt Nam có thể phân thành hai nhóm lớn - các bản đồ phục vụ công tác điều tra cơ bản và các bản đồ phục vụ quản lý lãnh thổ. Trong khi các bản đồ phục vụ điều tra cơ bản thường được thành lập trên phạm vi lớn, phân mảnh theo hệ thống phân mảnh của bản đồ địa hình thì bản đồ phục vụ quản lý lãnh thổ thường được thành lập trong phạm vi các vùng địa lý tự nhiên, vùng địa lý kinh tế xã hội hoặc theo đơn vị hành chính.

Lựa chọn phép chiếu bản đồ là giai đoạn quan trọng trong thiết kế bản đồ chuyên đề, tập bản đồ, đặc biệt là trong xây dựng quy định, quy phạm cho mỗi thể loại bản đồ. Việc lựa chọn phép chiếu bản đồ phụ thuộc vào nhiều yếu tố. Ngoài những yếu tố cần phải cân nhắc mức độ ảnh hưởng khi lựa chọn phép chiếu cho một bản đồ cụ thể như vị trí địa lý, kích thước, hình dạng đường bao, phương pháp thành lập, mục đích sử dụng, tỷ lệ, độ chính xác của bản đồ, nội dung, phương pháp thể hiện bản đồ, đặc điểm biến dạng của phép chiếu ...., điều kiện tiên quyết trong chọn lựa phép chiếu là khả năng được hỗ trợ trong các phần mềm đồ họa và GIS thông dụng.

Ngoại trừ một số loại bản đồ có yêu cầu đặc biệt về biên độ và phân bố biến dạng, ví dụ bản đồ hàng hải, hàng không, phép chiếu của thể loại bản đồ có phạm vi sử dụng lớn như bản đồ hành chính, bản đồ địa chính, các bản đồ chuyên đề tài nguyên môi trường và kinh tế - xã hội phục vụ mục đích tra cứu, quản lý nên được lựa chọn trong một tập hợp phép chiếu, múi chiếu giới hạn để thuận tiện trong thành lập và phối hợp sử dụng bản đồ. Các phép chiếu họ UTM với hệ số điều chỉnh biến dạng khác nhau được nhiều nước trên thế giới lựa chọn để thành lập bản đồ địa hình quốc gia. Bản đồ địa hình Việt Nam cũng được thành lập ở phép chiếu UTM với hệ số điều chỉnh biến dạng khác nhau. Do lãnh thổ Việt Nam có hình dạng kéo dài theo phương kinh tuyến, chiều rộng theo phương vĩ tuyến không quá $7^{\circ}$, các đơn vị hành chính cấp tỉnh có chiều rộng theo phương vĩ tuyến không quá $2^{\circ}$, phép chiếu hình trụ ngang đồng góc UTM với hệ số $\mathrm{k}$ phù hợp có thể 
thỏa mãn các yêu cầu về biến dạng chiều dài và diện tích cho bản đồ địa hình và đa số các loại bản đồ chuyên đề. (Xem bảng 1)

Công thức ước tính tỷ lệ chiều dài của các phép chiếu họ UTM có dạng:

$$
\mu=k\left(1+\frac{\lambda^{2}}{2} \cos ^{2} \varphi\left(1+\eta^{2}\right)\right)
$$

Tỷ lệ diện tích $p=\mu^{\underline{2}}$

Biến dạng chiều dài và diện tích (\%) được tính theo công thức:

$$
v_{m}=(\mu-1) \cdot 100 ; v_{p}=(p-1) \cdot 100
$$

Bảng 1 trình bày kết quả tính toán biến dạng chiều dài $\mathrm{v}_{\mathrm{m}}$ phép chiếu UTM với các hệ số điều chỉnh biến dạng khác nhau.

Cũng có thể sử dụng công thức giản tiện hơn để xác định tỷ lệ chiều dài và diện tích trên các phép chiếu họ UTM theo khoảng cách $\mathrm{y}_{\mathrm{m}}$ đến kinh tuyến trục:

$$
\mu=k\left(1+\frac{y^{2}}{2 R^{2}}\right) \quad ; \quad p=k^{2}\left(1+\frac{y^{2}}{R^{2}}\right)
$$

Bảng 2 dưới đây trình bày kết quả tính toán biến dạng chiều dài $v_{m}$ và khoảng cách đến kinh tuyến trục trong các phép chiếu UTM với hệ số $\mathrm{k}$ khác nhau theo công thức (2). (xem bảng 2).

\section{Các phương án phép chiếu cho bản đồ chuyên đề}

2.1. Múi chiếu dùng cho bản đồ địa hình, $k=0.9996$

Một số ngành và địa phương đã ban hành quy định về thành lập bản đồ chuyên đề trong phép chiếu UTM (bản đồ hiện trạng sử dụng đất [2], bản đồ tài nguyên nước ngầm [3]) với các múi chiếu $6^{\circ}, \mathrm{k}=0.9996$ theo quy định của Thông tư 973, tức là múi chiếu dùng cho hệ thống bản đồ địa hình với các kinh tuyến trục $105^{\circ}$ và $111^{\circ}$. Bản đồ với cơ sở toán học như vậy thuận tiện trong thành lập bản đồ bằng phương pháp thành lập bản đồ truyền thống có chuyển vẽ nội dung chuyên đề lên nền bản đồ địa hình và khi sử dụng kết hợp với bản đồ địa hình.

Bảng 1: Biến dạng chiều dài phép chiếu UTM

\begin{tabular}{|r|r|r|r|r|r|r|r|r|}
\hline \multicolumn{1}{|c|}{$\varphi$} & $|\Delta \lambda|=0$ & $|\Delta \lambda|=0.5$ & $|\Delta \lambda|=1$ & $|\Delta \lambda|=1.5$ & $|\Delta \lambda|=2$ & $|\Delta \lambda|=2.5$ & $|\Delta \lambda|=3$ \\
\hline \multicolumn{8}{|c|}{$\mathrm{k}=0.9999, \mathrm{v}_{\mathrm{m}}(\%)$} \\
\hline 24 & -0.010 & -0.007 & 0.003 & 0.019 & & & \\
\hline 20 & -0.010 & -0.007 & 0.003 & 0.020 & & & \\
\hline 16 & -0.010 & -0.006 & 0.004 & 0.022 & & & \\
\hline 12 & -0.010 & -0.006 & 0.005 & 0.023 & & & \\
\hline 8 & -0.010 & -0.006 & 0.005 & 0.024 & & \\
\hline \multicolumn{8}{|c|}{$\mathrm{k}=0.9996, \mathrm{v}_{\mathrm{m}}(\%)$} \\
\hline 24 & -0.040 & -0.037 & -0.027 & -0.011 & 0.011 & 0.039 & 0.074 \\
\hline 20 & -0.040 & -0.037 & -0.027 & -0.010 & 0.014 & 0.044 & 0.081 \\
\hline 16 & -0.040 & -0.036 & -0.026 & -0.008 & 0.016 & 0.048 & 0.087 \\
\hline 12 & -0.040 & -0.036 & -0.025 & -0.007 & 0.018 & 0.051 & 0.091 \\
\hline 8 & -0.040 & -0.036 & -0.025 & -0.006 & 0.020 & 0.053 & 0.094 \\
\hline \multicolumn{8}{|c|}{$\mathrm{k}=1.0000, \mathrm{v}_{\mathrm{m}}(\%)$} \\
\hline 24 & 0.000 & 0.003 & 0.013 & 0.029 & 0.051 & 0.079 & 0.114 \\
\hline 20 & 0.000 & 0.003 & 0.013 & 0.030 & 0.054 & 0.084 & 0.121 \\
\hline 16 & 0.000 & 0.004 & 0.014 & 0.032 & 0.056 & 0.088 & 0.127 \\
\hline 12 & 0.000 & 0.004 & 0.015 & 0.033 & 0.058 & 0.091 & 0.131 \\
\hline 8 & 0.000 & 0.004 & 0.015 & 0.034 & 0.060 & 0.093 & 0.134 \\
\hline
\end{tabular}


Tuy nhiên, một số khu vực ở rìa múi chiếu, tức là dọc kinh tuyến $108^{\circ}$ sẽ phải chịu biến dạng lên đến $0.094 \%$ (chiều dài trên bản đồ lớn hơn chiều dài trên mặt ellipsoid), trong khi rất nhiều khu vực nằm dọc kinh tuyến $105^{\circ}$ chịu biến dạng - $0.04 \%$ (chiều dài trên bản đồ nhỏ hơn chiều dài trên mặt ellipsoid).

Một số tỉnh nằm dọc kinh tuyến $108^{\circ}$ sẽ phải thành lập bản đồ trên hai múi chiếu. Với phương án mở rộng múi chiếu, một số khu vực trên bản đồ tỷ lệ 1: 25000 sẽ phải chịu biến dạng chiều dài lên đến $0.17 \%$
(Quảng Nam, Lâm Đồng). (xem bảng 3).

\subsection{Kinh tuyến trục $105^{\circ}$}

Ưu điểm của phương án này là múi chiếu thống nhất cho tất cả các tỉnh và các vùng địa lý. Khu vực cách xa kinh tuyến trục là các tỉnh duyên hải Nam trung bộ có biến dạng chiều dài tối đa đạt tới $0.3 \%$ với hệ số điều chỉnh $\mathrm{k}=1$ hoặc $0.26 \%$ với $\mathrm{k}=0.9996$

\subsection{Kinh tuyến trục địa phương đí qua} vùng trung tâm của tỉnh, $k=1$

Do các tỉnh của Việt Nam có chiều rộng

Bảng 2: Biến dạng chiều dài và diện tích theo khoảng cách đến kinh tuyến trục

\begin{tabular}{|c|c|c|c|c|c|c|c|c|c|}
\hline $\mathbf{y}(\mathbf{k m})$ & $\mathbf{0}$ & $\mathbf{5 5}$ & $\mathbf{9 0}$ & $\mathbf{1 1 0}$ & $\mathbf{1 6 5}$ & $\mathbf{1 8 0}$ & $\mathbf{2 2 0}$ & $\mathbf{2 5 0}$ & $\mathbf{3 3 0}$ \\
\hline $\mathrm{k}=0.9999, \mathrm{v}_{\mathrm{m}}(\%)$ & -0.010 & -0.006 & 0.000 & 0.005 & 0.024 & & & & \\
\hline $\mathrm{k}=0.9996 \mathrm{v}_{\mathrm{m}}(\%)$ & -0.040 & -0.036 & -0.030 & -0.025 & -0.006 & 0.000 & 0.020 & 0.053 & 0.094 \\
\hline $\mathrm{k}=1.0000, \mathrm{v}_{\mathrm{m}}(\%)$ & 0.000 & 0.004 & 0.010 & 0.015 & 0.034 & 0.040 & 0.060 & 0.093 & 0.134 \\
\hline $\mathrm{k}=0.9999, \mathrm{v}_{\mathrm{p}}(\%)$ & -0.020 & -0.013 & 0 & 0.010 & 0.047 & & & & \\
\hline $\mathrm{k}=0.9996 \mathrm{v}_{\mathrm{p}}(\%)$ & -0.080 & -0.073 & -0.06 & -0.050 & -0.013 & 0 & 0.039 & 0.106 & 0.188 \\
\hline $\mathrm{k}=1.0000, \mathrm{v}_{\mathrm{p}}(\%)$ & 0.000 & 0.007 & 0.020 & 0.030 & 0.055 & 0.080 & 0.119 & 0.186 & 0.268 \\
\hline
\end{tabular}

Bảng 3: Các tỉnh nằm trên hai múi chiếu $6^{\circ}$ và biến dạng chiều dài tối đa cho phương án múi $6^{\circ}$ mở rộng

\begin{tabular}{|l|c|c|c|r|r|}
\hline \multicolumn{1}{|c|}{ Tỉnh } & $\lambda_{\min }$ & $\lambda_{\max }$ & $\begin{array}{c}\text { kinh } \\
\text { tuyến } \\
\text { trục }\end{array}$ & $\begin{array}{c}\mathrm{y}_{\max } \\
(\mathrm{km})\end{array}$ & $\begin{array}{c}\mathrm{v}_{\mathrm{m} \max } \\
(\%)\end{array}$ \\
\hline Quảng Ninh & 106.43522 & 108.0991 & 105 & 341 & 0.103 \\
\hline TT Huế & 107.01250 & 108.2034 & 105 & 352 & 0.113 \\
\hline Đà Nẵng & 107.81478 & 108.3409 & 105 & 367 & 0.126 \\
\hline Quảng Nam & 107.20144 & 108.7506 & 105 & 413 & 0.170 \\
\hline Bình Thuận & 107.39034 & 108.9842 & 111 & 397 & 0.154 \\
\hline Kon Tum & 107.32887 & 108.5607 & 105 & 392 & 0.149 \\
\hline Gia Lai & 107.44276 & 108.8953 & 111 & 391 & 0.148 \\
\hline Đắk Lắk & 107.47673 & 109.0067 & 111 & 388 & 0.145 \\
\hline Đắk Nông & 107.20198 & 108.1241 & 105 & 344 & 0.106 \\
\hline Lâm Đồng & 107.26224 & 108.7311 & 105 & 410 & 0.167 \\
\hline
\end{tabular}


theo phương vĩ tuyến không lớn $\left(\Delta \lambda \approx 1.93^{\circ}\right.$ tại Nghệ An), với lựa chọn kinh tuyến trục địa phương đi qua vùng trung tâm của tỉnh và $\mathrm{k}=1$, các tỉnh nằm trọn trong vùng có biến dạng và diện tích nhỏ. Biến dạng tối đa $(0.025 \%)$ có mặt dọc kinh tuyến $107^{\circ}$ tại khu vực cực đông huyện Cát Hải tỉnh Hải Phòng. Nhược điểm của phương án này là không thuận tiện khi sử dụng kết hợp với hai hệ thống bản đồ đã thành lập - bản đồ địa hình và bản đồ địa chính.

\subsection{Kinh tuyến trục địa phương dùng} cho bản đồ địa chính, $k=0.9999$ (phép chiếu bản đồ địa chính)

Quy định kinh tuyến trục các múi chiếu địa phương dùng cho bản đồ địa chính của Thông tư 973 đảm bảo phần lớn diện tích mỗi tỉnh nằm trong vùng có biến dạng độ dài và diện tích nhỏ nhất (cách kinh tuyến trục từ 60 đến $110 \mathrm{~km}$ ). Với các tỉnh có $\Delta \lambda \approx 2^{\circ}$ (Nghệ An, Thanh Hóa), việc lựa chọn kinh tuyến trục đã ưu tiên vùng ven biển, nợ tập trung dân cư nằm trong khu vực có biến dạng thấp nhất, ngoài ra cũng ưu tiên chọn kinh tuyến trục trùng với kinh tuyến trục bản đồ địa hình tỷ lệ $1: 10.000$ và lớn hơn để tránh các khác biệt giữa các hệ thống bản đồ. Với đa số các tỉnh (51/63), kinh tuyến này không đi qua vùng trung tâm của tỉnh.

Với lựa chọn này, các tỉnh cũng nằm trọn trong vùng có biến dạng và diện tích nhỏ, tất cả các tỉnh đều có biến dạng chiều dài nằm trong khoảng từ $-0.01 \%$ đến $0.014 \%$ (tỉnh Lâm Đồng), ngoại trừ biến dạng tối đa $(0.015 \%)$ có mặt dọc kinh tuyến $107^{\circ}$ tại khu vực cực đông huyện Cát Hải tỉnh Hải Phòng. Ngoài ra, phương án này đảm bảo sự thống nhất về cơ sở toán học của hệ thống bản đồ phục vụ quản lý.

\subsection{Kinh tuyến trục địa phương dùng cho bản đồ địa chính, $k=0.9996$}

Với phương án được một số đơn vị lựa chọn trong thành lập bản đồ chuyên đề cấp tỉnh là sử dụng phép chiếu với $k=0.9996$, kinh tuyến trục địa phương bản đồ địa chính cho các bản đồ tỷ lệ 1:25.000 và nhỏ hơn (Bản đồ hành chính [4], Bản đồ tài nguyên nước dưới đất [3]), các ưu điểm của lựa chọn kinh tuyến trục cho từng địa phương theo Thông tư 973 hoàn toàn mất tác dụng. Đó là do phép chiếu UTM với $k=0.9999$ cho biến dạng nhỏ nhất về cả chiều dài lẫn diện tích ở khu vực từ 60 đến $110 \mathrm{~km}$ cách kinh tuyến trục, trong khi đó phép chiếu với $\mathrm{k}=0.9996$ ở vùng từ 150 đến $210 \mathrm{~km}$ cách kinh tuyến trục có biến dạng tối ưu.

So sánh các phương án phép chiếu dùng cho nhóm bản đồ chuyên đề cấp tỉnh trở xuống: (xem bảng 4), ta thấy phương án được nhiều đơn vị lựa chọn trong thành lập bản đồ chuyên đề cấp tỉnh - phép chiếu với $k=0.9996$, kinh tuyến trục địa phương bản đồ địa chính - là phương án có nhiều nhược điểm về giá trị, phân bố biến dạng và không có ưu điểm trong phối hợp thành lập và sử dụng với hệ thống bản đồ địa hình cũng như địa chính. Với phương án này, mỗi tỉnh sẽ có 4 hệ thống bản đồ: bản đồ địa hình tỷ lệ lớn với $k=0.9999$, bản đồ địa hình tỷ lệ $1: 25.000$ và nhỏ hơn với $\mathrm{k}=0.9996$, bản đồ địa chính với kinh tuyến trục địa phương, $\mathrm{k}$ $=0.9999$ và các bản đồ chuyên đề với kinh tuyến trục địa phương, $\mathrm{k}=0.9996$.

Phương án sử dụng phép chiếu bản đồ địa chính cho các bản đồ chuyên đề cấp tỉnh tất cả các tỷ lệ có thể làm giảm khó khăn trong phối hợp sử dụng các hệ thống bản đồ với cơ sở toán học khác nhau trong công tác quản lý ở cấp địa phương. Phương án này đã được đề xuất trong [5] và được Tổng cục Quản lý đất đai lựa chọn để thành lập các bản đồ hiện trạng sử dụng đất trong kỳ Tổng kiểm kê, thống kê đất đai 2015 [6].

\section{Kết luận}

Một trong các yếu tố quan trọng cần phải xem xét trong lựa chọn phép chiếu cho bản đồ chuyên đề là khả năng được hỗ trợ trong 
Bảng 4: So sánh các phương án phép chiếu dùng cho nhóm bản đồ chuyên đề cấp tỉnh

\begin{tabular}{|c|c|c|c|}
\hline Stt & Phương án & Ưu điểm & Nhược điểm \\
\hline 1 & $\begin{array}{l}\text { Múi chiếu dùng cho bản đồ địa } \\
\text { hình, } \mathrm{k}=0.9996\end{array}$ & $\begin{array}{l}\text { Phối hợp thuận tiện với } \\
\text { bản đồ địa hình }\end{array}$ & Một số tỉnh nằm trên hai múi chiếu \\
\hline 2 & Kinh tuyến trục $105^{\circ}$ & $\begin{array}{l}\text { Phép chiếu thống nhất } \\
\text { toàn quốc }\end{array}$ & Biến dạng lớn ở rìa múi chiếu \\
\hline 3 & $\begin{array}{l}\text { Kinh tuyến trục địa phương đi } \\
\text { qua vùng trung tâm cưa tinh, } \mathrm{k}=1\end{array}$ & Biến dạng nhó & $\begin{array}{l}\text { Phối hợp không thuận tiện với các hệ } \\
\text { thống đang sứ dụng }\end{array}$ \\
\hline 4 & $\begin{array}{l}\text { Kinh tuyến trục địa phương dùng } \\
\text { cho bản đồ địa chính, } \mathrm{k}=0.9999\end{array}$ & $\begin{array}{l}\text { Biến dạng nhó, phối } \\
\text { hợp thuận tiện với hệ } \\
\text { thống bản đồ địa chính }\end{array}$ & $\begin{array}{l}\text { Không thuận tiện khi phối hợp sử dụng } \\
\text { bản đồ giữa các tinh }\end{array}$ \\
\hline 5 & $\begin{array}{l}\text { Kinh tuyến trục địa phương dùng } \\
\text { cho bản đồ địa chính, } \mathrm{k}=0.9996\end{array}$ & Không có & $\begin{array}{l}\text { Biến dạng lón. Không thuận tiện trong } \\
\text { phối hợp với bản đồ địa hình và địa chính }\end{array}$ \\
\hline
\end{tabular}

các phần mềm đồ họa và GIS thông dụng. Ngoài ra, việc lựa chọn phép chiếu cho một hệ thống bản đồ cũng cần phải cân nhắc mức độ thuận tiện trong sử dụng phối hợp với hệ thống bản đồ địa hình và bản đồ địa chính.

Phương án sử dụng phép chiếu UTM với $\mathrm{k}=0.9999$ và kinh tuyến trục địa phương cho bản đồ chuyên đề cấp tỉnh trở xuống đảm bảo biến dạng chiều dài và diện tích tối ưu cho tất cả các tỉnh. Phương án này cũng thuận tiện cho công tác thành lập và sử dụng kết hợp bản đồ chuyên đề các tỷ lệ và các cấp tại địa phương. $O$

\section{Tài liệu tham khảo}

[1]. Thông tư 973/2001/TT-TCĐC của Tổng cục địa chính ngày 20/06/2001 về hướng dẫn áp dụng hệ quy chiếu và hệ tọa độ quốc gia VN-2000.

[2]. Quy định về thành lập bản đồ hiện trạng sử dụng đất ban hành kèm Quyết định số 22/2007/QĐ-BTNMT ngày 17/02/2007 của Bộ trưởng Bộ Tài nguyên và Môi trường.

[3]. Thông tư 15/2013/TT-BTNMT ngày 15/06/2013 của Bộ Tài nguyên và Môi trường Quy định kỹ thuật lập bản đồ tài nguyên nước dưới đất tỷ lệ 1:50000.

[4]. Thông tư 47/2014/TT-BTNMT ngày 22/08/2014 của Bộ Tài nguyên và Môi trường Quy định kỹ thuật thành lập bản đồ hành chính các cấp.

[5]. Đồng Thị Bích Phương. Bàn về phép chiếu dùng cho bản đồ hiện trạng sử dụng đất. Tạp chí Khoa học Trắc địa và Bản đồ, số 20-2014.

[6]. Thông tư 28/2014/TT-BTNMT ngày 02/06/2014 của Bộ Tài nguyên và Môi trường Quy định về thống kê, kiểm kê đất đai và lập bản đồ hiện trạng sử dụng đất. $O$

\section{Summary}

\section{About projection for thematic map of provinces}

\section{Dr. Dong Thi Bich Phuong}

\section{Vietnam Institute of Geodesy and Cartography}

This paper clarifies a number of factors affecting the choice of map projection for thematic map and proposes using transverse mercator projection with $\mathrm{k}=0.9999$ and local central meridian for maps of provinces, districts and communes. $O$

Ngày nhận bài: 10/12/2014. 